\title{
Hurricane by Proxy
}

\author{
Wilmarie Cidre Serrano $^{1}$
}

Received: 3 March 2018 / Accepted: 2 May 2018 / Published online: 14 May 2018

(C) Academic Psychiatry 2018

Three long days passed before I was able to hear my mother's voice on the other side of the phone. Hundreds of unanswered calls. Two sleepless nights, tears, puffy eyes.

"Hola?" That was definitely her voice. My neck muscles relaxed and I was finally able to breathe. My mom had survived the storm.

Hurricane Maria made landfall in Puerto Rico on September 20, 2017. Its category 4, 155-mile per hour winds shook the island, uprooted homes, and destroyed Puerto Rico's electrical system, making it the worst hurricane to hit Puerto Rico in over 80 years. I was in California at the time of the hurricane. As a second-year psychiatry resident at Stanford, I was taking care of patients in the involuntary psychiatric unit while Maria ransacked my island.

"Todo bien" my mother declared softly. In a calm voice, she shared that nothing severe had happened to our home in San Juan. Some palm trees fell, but none on top of the house. The first floor flooded, but my mother's constant sweeping kept most of the potential damages at bay. She had spent the hurricane alone in her house with the deafening rattle of what felt like an endless tornado. I was afraid she would slip during the storm and someone would find her days later alone and hurt. I did not want to think of death. "Todo bien," she repeated, "Todo bien."

I woke up days later drenched in sweat, with images in my mind of my island drowning in a sea of blood. After Maria, I searched desperately for information on how my island was doing. I read about how Puerto Ricans waited in lines for 12 hours at supermarkets and gas stations. Water was being rationed in the supermarket nearest to my mother's house. Dialysis patients died without access to treatment, and infections as rare as leptospirosis started to claim lives. My island was bleeding and I felt helpless, wounded, and angry.

${ }^{1}$ Spanish for everything's okay

Wilmarie Cidre Serrano

wcidre@stanford.edu

1 Stanford University, Stanford, CA, USA
In California, my life continued-seemingly normally. I woke up at 6 a.m. every day and continued the job that I usually love. Yet, Puerto Rico was always on my mind. And I seemed to be uncharacteristically on edge. It was hard to concentrate on anything but Puerto Rico and I often cried at night. "How's your family doing?", so many of my wellmeaning friends and co-workers asked. My heart felt like it was stuck in my throat. I swallowed and swiftly changed the subject. "Todo bien..." I didn't want to talk about Puerto Rico.

Maria has, dare I say it, traumatized me. Yet, I feel like I don't have the right to feel traumatized. For one, as a psychiatrist, the word traumatized certainly evokes associations with trauma-related disorders that I am fortunately not experiencing. Even though I was having nightmares, changes in concentration, irritability, and feelings of guilt for over a month after Maria, none of these symptoms interfered with my functioning and I didn't meet criteria for a stressor-related disorder, including PTSD. I feel guilty even thinking that I feel traumatized because I didn't experience Maria directly and my family, who did, survived it without major losses. Even worse, I left Puerto Rico over a decade ago. It feels selfish for me to write this piece when I know that in Puerto Rico, there are still hundreds of thousands of people without a roof over their heads and no access to clean water or food. It feels quite selfish to cry in my air-conditioned apartment while I know that in Puerto Rico, people line up for hours to buy a small bag of ice. It feels as if I don't care about my people because I'm not there.

I've tried to brush off my guilt, but it somehow always resurfaces. I used to think of guilt as an emotion that follows a transgression and separates the transgressor from the victim and humanity at large. In fact, if asked a year ago about the utility of guilt, I would have confidently responded that it is typically useless, divisive, and, for me, a remnant of my Catholic mea culpa upbringing. Yet, after Maria, I was haunted by it. How could I feel guilty about a natural disaster that I obviously didn't cause and I didn't even experience?

Maria has taught me that guilt is all but uncommon after traumatic events. The guilt I felt seemed to be a variant of survivor's guilt, or that felt by those who survive a traumatic 
event while others do not. And there is beauty in this guilt. When identified and explored, guilt can serve as a useful signal to the guilty as it often highlights the violation of an important value. Realizing this can help us align our values with our actions. Additionally, guilt can help connect us to our communities. Baumeister et al. describe guilt as a social emotion; guilt "strengthens social bonds by eliciting symbolic affirmation of caring and commitment" [1]. My guilt signaled that my heart was with my mother and the Puerto Rican people, my people, and I wanted to be there with them.

My experience of Maria has also helped me better understand and empathize with my patients with PTSD. And, as I've learned, trauma impacts not only individuals who suffer or witness the trauma directly, but also those who experience it indirectly - even people thousands of miles away. In fact, according to the DSM-5 criteria for PTSD, direct exposure to trauma is but one of four routes to PTSD. The other three being the following: witnessing trauma, learning that a relative or close friend was exposed to trauma, and indirect exposure to aversive details of the trauma [2]. The effects of national traumas like September 11 have been well studied and reveal a similar pattern. A 2002 JAMA study on the psychological impact of September 11 on a national sample of 3496 American adults revealed that $17 \%$ of adults who lived outside of New York and experienced the attacks indirectly reported symptoms of PTSD two months after September 11 [3].

It's now four months after Maria and half of Puerto Rico remains in the dark. "Todo bien," I repeated to myself for weeks after the storm. Yet, the same unforgiving winds that unveiled my island's poverty and aging infrastructure have uncovered my inescapable heartache.

Recognizing this heartache has not been easy for me. In fact, the first person to recognize and address my distress after Maria wasn't me, but one of my residency mentors. She noticed that I didn't seem like myself and brought it up. And I'm so grateful that she did as I fear that I would have otherwise continued in avoidance. Opening up this conversation has allowed me to write about my experience of Maria and reconnect with my island of Puerto Rico to find ways of helping my people. In a time of increasing focus on resident well-being, I have learned that residents and residency educators share the responsibility of getting to know each other and fostering a culture of openness, psychological well-being, and connection. Only this way can co-residents, educators, and program directors more easily identify when resident well-being might be threatened, either for causes related or extraneous to residency itself, and feel comfortable and connected enough to bring it up.

My experience of Maria is likely far from atypical. There are now more Puerto Ricans in the USA than on the island itself. Florida alone has received an influx of over 200,000 Puerto Ricans moving there since Maria [4]. We are a people displaced. And when those we leave behind suffer, we suffer by proxy - and often in hiding. I hope writing about this serves as light to others who also live far away from their homes and might be struggling with similar emotions, so that we can step out of the darkness and seek support from our communities, hopefully without the wind's unwanted coaxing.

Acknowledgements I would like to thank Dr. Laura Dunn, Dr. Carolyn Rodriguez, and Dr. Belinda Bandstra for their guidance and support.

\section{Compliance with Ethical Standards}

Disclosures The author states that there is no conflict of interest.

\section{References}

1. Baumeister RF, Stillwell AM, Heatherton TF. Guilt: an interpersonal approach. Psychol Bull. 1994;115:243-67.

2. Trauma- and Stressor-Related Disorders. Diagn Stat Man Ment Disord DSM-5. 2013. https://dsm.psychiatryonline.org/doi/abs/10. 1176/appi.books.9780890425596.dsm07. Accessed 20 Dec 2017.

3. Silver RC, Holman EA, McIntosh DN, Poulin M, Gil-Rivas V. Nationwide longitudinal study of psychological responses to September 11. JAMA. 2002;288:1235-44.

4. Sesin C Over 200,000 Puerto Ricans have arrived in Florida since Hurricane Maria [Internet]. NBC News. 2017 [cited 2017 Dec 8]. Available from: https://www.nbcnews.com/news/latino/over-200000-puerto-ricans-have-arrived-florida-hurricane-maria-n825111 